\title{
O rebanho de Hobbes
}

\section{CLAUDio BEATO ${ }^{I}$}

L

UGARES têm sentimentos? Orhan Pamuk utiliza-se do termo hüzün, o estado de melancolia e estado de alma dos istambulis, condenados a viver entre as ruínas do glorioso passado do Império Otomano e a decadente Turquia de sua infância. Esse simbolismo da decadência despertava um estado de "melancolia das ruínas", visto primeiro como pitoresco, terminava por exprimir a tristeza do séculos de derrota e pobreza, e da destruição do Império Otomano (cap.26).

Tristesse traduzia a tristeza e melancolia que Lévi-Strauss (1980) utilizou para referir-se à pobreza dos tristes trópicos. O jovem e talentoso filósofo que emigrara para São Paulo na esperança de ter à mão o material para o etnógrafo que viria a reencarnar no filósofo se vê no meio de uma metrópole de dândis que rechaçavam quaisquer traços de indígenas. Tivera que ir buscar então longe da metrópole, no meio da selva do Mato Grosso, onde, ao escutar a bela melodia de Chopin, se dá conta com tristeza do quão temerário fora a escolha que fizera.

De qual termo lançaríamos mão para nos referir aos sentimentos dos habitantes dos grandes centros urbanos brasileiros? Certamente uma das primeiras e incômodas reflexões que inauguraram nosso universo de sensações acerca da violência urbana foram descritas naquele que era um dos contos preferidos de Clarice Lispector (1979): "Mineirinho", ao discutir sobre o fuzilamento com treze tiros de um conhecido criminoso carioca da época. A descrição dos sucessivos sentimentos despertados pela notícia é perturbadora.

Esta é a lei. Mas há alguma coisa que, se me faz ouvir o primeiro e o segundo tiro com um alívio de segurança, no terceiro me deixa alerta, no quarto desassossegada, o quinto e o sexto me cobrem de vergonha, o sétimo e o oitavo eu ouço com o coração batendo de horror, no nono e no décimo minha boca está trêmula, no décimo primeiro digo em espanto o nome de Deus, no décimo segundo chamo meu irmão. O décimo terceiro tiro me assassina - porque eu sou o outro. Porque eu quero ser o outro.

Desassossego que se transforma em vergonha, horror, e termina na angústia em compreender a violência da própria justiça. Para que tantos tiros, quando apenas um bastaria? Pergunta-se a escritora muitos anos depois. Para vivermos, era necessário nos tornarmos "sonsos essenciais".

Mas quais sentimentos contemporâneos que nossas cidades suscitam? Eles mesclam-se além do triste espetáculo da miséria de nossas gigantescas favelas, com o medo que é onipresente na vida dos habitantes das grandes cidades latino-americanas. Não convivemos com as ruínas de uma civilização pretérita, 
mas assistimos à construção das ruínas de uma sociedade pela violência, nas quais formas tradicionais de sociabilidade dão lugar à desconfiança, medo e ao individualismo. A rigor, não se trata de algo novo em sua essência, pois sempre guardamos as marcas na nossa história da exclusão espacial de grandes parcelas de nossa população, relegadas ao degredo social no espaço de poucos quarteirões de vizinhanças nobres, e o temor hobbesiano da morte violenta.

Pamuk descreve como um habitante de Istambul, em contraste com os suíços, orientaria estrangeiros em suas cidades: "vá por aquelas ruínas...” no caso de Istambul, ou "siga até aquela ponte esplêndida" no caso suíço. Em nossas cidades tais informações certamente seriam complementadas por cautelas em relação a certos espaços ou grupos de pessoas, de forma a introduzir o medo e a insegurança como consortes nas jornadas urbanas. Curiosamente, alguns aplicativos de locomoção nos grandes centros têm ignorado essas cautelas, e conduzido inadvertidos motoristas a regiões sinistras.

Como podemos apreender esses mapas cognitivos. Quais os elementos mais salientes que o compõem? Como são construídos? Sabemos que o temor de ser vítima de perdas patrimoniais é acompanhado pari passu pelo medo da morte. Nossos mapas cognitivos são compostos de mapas e regiões de medo que nos guiam estigmatizando grupos e territórios. Todo discurso político de se portar armas utilizou-se desse artifício para conseguir o apoio do rebanho hobbesiano, temeroso da morte violenta, e a ira de guardiões contra supostos predadores.

\section{Onde acontecem as mortes violentas?}

Calvino, nas Cidades invisípeis, narra cidades imaginárias que o imperador Kublai Khan recria em sua mente e traduzidas por Marco Polo, numa cartografia imaginária. São todas cidades com nome de mulheres. Muitas vezes, essas descrições eram feitas por mímicas, apontando-se objetos, utilizando símbolos e emblemas para a compreensão do imperador: $\mathrm{O}$ novo dado ganhava um sentido daquele emblema e ao mesmo tempo acrescentava um novo sentido ao emblema. O império, pensou Kublai, "talvez não passe de um zodíaco de fantasmas da mente". Nossas cidades, tais como as de Calvino, são habitadas por personagens sem nome que, ao nos dizer como vivem e onde vivem, terminam compondo o mosaico geográficos das nossas possibilidades de desenvolver formas de autocontrole, terminam por apontar nossas chance de diminuir e, quem sabe, expulsar o medo hobbesiano da morte violenta. Mas onde essas mortes acontecem?

Quaisquer estatísticas de homicídios no mundo exporão cifras alarmantes em algumas regiões do globo, mas a América Latina e os Estados Unidos destacam-se notavelmente. Mais de um terço dos quase meio milhão de assassinatos no planeta ocorre nas Américas. ${ }^{1}$ Mesmos os Estados Unidos destacam-se como o mais violento dentre os países mais desenvolvidos, especialmente em relação à Europa e à Ásia. O uso de armas de fogo causa vítimas em proporções incomparáveis com outros países no mesmo grau de desenvolvimento. No caso da América Latina, entretanto, o destaque é notável. 
Existem significativos esforços para compreender as razões dessa concentração em nossa região. Por ora, gostaria de destacar apenas o aspecto da concentração espacial dessa endemia. Estamos falando de países e estados com graves problemas institucionais e no sistema de justiça criminal e prisional, mas cujas mortes violentas sucedem quase monotonamente obedecendo aos mesmos padrões territoriais e temporais. Existem razões socioeconômicas de fundo que amparam essa concentração socioespacial em algumas cidades, e territórios no interior delas (Beato, 2012). San Salvador em El Salvador; Tijuana e Acapulco no México; Tegucigalpa e San Pedro Sula em Honduras; Manaus, Porto Alegre e Maceió no Brasil; Guatemala City Villa Nueva; Cape Town na África do Sul; Baltimore nos Estados Unidos; Cali e Palmira na Colômbia; San Juan em Puerto Rico; e Kingston na Jamaica são as cidades arroladas no rank de março de 2017 pelo The Economist. ${ }^{2} \mathrm{O}$ senso comum aponta como causa imediata o narcotráfico, mas análises mais detalhadas mostram um quadro mais variado e complexo, no qual se destacam profundas distorções socioeconômicas, ambientes urbanos deteriorados e sistemas de justiça em situação falimentar.

Cidades são territórios heterogêneos, complexos e diversificados. Compreendê-las é um exercício de linguagem intenso e denso, pois implica construir diferentes narrativas para um mesmo território. Na analogia apropriada de Wittgenstein (1980, par.18), "Nossa linguagem pode ser considerada como uma velha cidade: uma rede de ruelas e praças, casas novas e velhas, e casas construídas em diferentes épocas; e isto tudo cercado por uma quantidade de novos subúrbios com ruas retas e regulares e com casas uniformes". A linguagem que descreve as cidades, seus territórios e mazelas padece das mesmas estratégias interpretativas de outras formas, tais como a filosofia, a matemática, a geografia ou a criminologia. Alguns lugares são mais uniformes que outros e podem ser visitados desde que tenhamos orientações adequadas de como transitarmos ali: um mapa que nos diga o sentido que devemos tomar, qual a direção, em que momento etc. São instruções nos conduzindo a trajetos que, ao percorrê-los, percebemos que nos fornecem uma paisagem característica do mundo que nos cerca. Nosso desafio é compreender as orientações adequadas acerca de como transitar nesse universo ao mesmo tempo linguístico, mas permeado por violência e morte. Não existe um mirante ou uma posição privilegiada para entendermos todas as suas facetas. A descrição é inseparável do que é descrito.

A distopia latino-americana descreve cidades violentas emolduradas por comunidades desorganizadas vivendo em territórios dominados por gangues e grupos mais ou menos organizados que utilizam da violência de forma instrumental. São o palco de espetáculo desolador, no qual falhas socioeconômicas e institucionais se sobrepõem, fornecendo o combustível para o florescimento da desconfiança sob a égide do medo e da morte violenta de um estado da natureza hobbesiano. Compreender essa conjunção de sentimentos e fatos é desafio a que gerações de analistas, estudiosos, escritores e cientistas têm se dedicado ao 
longo de décadas. Como espaços urbanos degradados relacionam se à emergência de grupos de jovens desocupados em locais deteriorados, com baixo grau de autocontrole e armas nas mãos, com disposição para cometer toda sorte de violência e crueldade, bem como se tornarem vítimas delas? Gangues e organizações mais ou menos estruturadas terminam produzindo toda sorte de vítimas externas e em seu interior. São imagens dramáticas relacionadas à deterioração da qualidade de vida dos moradores dos centros urbanos na América Latina. Se para mais de um terço $(36 \%)$ da população latino-americana, as sucessivas crises econômicas vêm atormentando a vida das pessoas, a violência tem se tornado o tópico número 1 em diversos países. Para 33\% é o principal problema, numa proporção que vem crescendo desde 2004. Para os habitantes de Trinidad e Tobago, El Salvador, Uruguai, Jamaica, Honduras, Peru, Guatemala esse é o principal problema de seus países. ${ }^{3}$

Existem cidades e países, como Honduras, que adquiriram reputação mundial pelos altos níveis de violência. Ao vermos o mapa da distribuição de crimes, vemos que existem muitas regiões no país virtualmente pacíficas. Essa concentração ocorre, num aparente paradoxo, nas maiores e mais desenvolvidas cidades do país. Em sua capital, Tegucigalpa, e me San Pedro Sula, bem como nas principais cidades, existem horários em que grupos saem às ruas para recolher o "impuesto de guerra", como é chamada a extorsão sistemática praticada pelas "maras" locais. Coisas de "failed states"? Não necessariamente. Uma dos problemas dos aplicativos de GPS em cidades como o Rio de Janeiro é quando conduzem veículos para áreas violentas dominadas por traficantes ou milicianos. Várias cidades contam com extensões territoriais nas mãos de alguma forma de poder paralelo, numa estratégia de ação só é possível em locais onde falharam muitas coisas.

Mas existe uma lógica nisso que obedece a um princípio quase universal, e bastante recorrente também em outros países latino-americanos, segundo a qual a violência obedece a uma distribuição de Pareto, concentrando se em algumas regiões do país, e em alguns territórios das grandes cidades. Uma das curiosidades dessa distribuição é que diferentes tipos de delitos e formas de violência obedecem a determinantes distintos nos territórios em que se manifestam. Em alguns casos, mais concentração de riqueza e desenvolvimento parece explicar mais a concentração do que em outros espaços, onde pobreza e miséria atraem outros tipos de crimes.

Esse padrão nos remete a outra das Cidades invisiveis de Ítalo Calvino: Melania. Sua maior característica são diálogos que se sucedem aos pedaços, recitados infinitamente, mas por personagens distintos. Sempre que alguém visita a cidade, encontrará a mesma conversa, mas recitadas por outros atores. O enredo é basicamente o mesmo, repetindo-se de forma quase aborrecida. Quem analisa a distribuição espaçotemporal de crimes conhece bem essa reiteração persistente. Compreender essas peças que, tal como a cidade descrita por Marco Polo, são como pedras que compõem o arco de uma ponte nos ajudaria a apreender as 
razões da monotonia infinita e, quem sabe, evitá-las? A complexidade que buscamos desvendar na explicação da violência e do medo nas cidades deveria ser orientada pela mesma recomendação de Kublai Khan a Marco Polo - "Porque falar das pedras? Só o arco me interessa" (Calvino, 1990: p.51). Boa parte do pensamento criminológico mais recente dedica-se à análise dos locais (places) e das formas de intervir de forma eficiente e qualificada (Weisburd et al., 2012). Os padrões insistentemente recorrentes são desafios para compreendermos suas estruturas, bem como os fundamentos que as sustentam.

Nossas geografias do medo parecem ser universais, manifestando-se em todos os espaços e territórios de uma cidade, uma região ou de bairros. Não é apenas de uma "sensação de insegurança", para utilizarmos uma expressão tão ao gosto dos gestores e policy makers, como se essa geografia subjetiva não encontrasse amparo em fatos e dados. Análise feita a partir de dados da I Pesquisa nacional de Vitimização, de 2012, mostrou que existe uma tensão latente entre os sentimentos de medo e a avaliação das pessoas acerca do risco de se tornarem vítimas de diferentes tipos de crime. De $30 \%$ a $40 \%$ da população de mais de 15 anos temem ser vítimas de agressão, ter objetos roubados ou ter sua residência invadida ou ser sequestradas, dentre outros crimes. É surpreendente o elevado número de pessoas que temem ser assassinadas no país (quase $50 \%$ ), e $27 \%$ acreditam que isso pode ocorrer nos próximos doze meses (Crisp, 2012). Quanto deixamos de conviver com as pessoas, frequentar locais públicos, e temos receio de falar com pessoas, ou cruzar com estranhos anônimos em alguma rua mais deserta é porque o medo passou a ser um elemento constitutivo das relações sociais, deteriorando drasticamente a qualidade de vida urbana.

\section{Deterioração urbana e concentração da violência}

A concentração denota uma das maiores marcas da deterioração urbana de nossas cidades. Mais que isso, traduz a incapacidade de gestores em planejar com base nas fartas evidências que apontam quais locais e horários os crimes ocorrem. Jack Maple (1999), um dos responsáveis pela operacionalização do modelo Compstat em Nova York, dizia em The crime fighter que os mapas gerados mostravam onde estavam concentrados os pesqueiros dos "peixes" grandes e pequenos (Bratton, 1998). Muitas vezes suas localizações contrariavam o senso comum de operadores e do público. Era como um holofote a iluminar locais em que se deve atuar, para além da sensação subjetiva de nossos medos. Esses locais de desordem e degradação ilustrariam nossa baixa capacidade de controle de ambientes urbanos (Sampson, 2012), retratando a nostalgia de uma "comunidade purificada" ao qual Sennet (1970) se referia.

Muitas das estratégias mais bem-sucedidas de controle do crime e aumento da sensação de segurança vieram da focalização de diversas ações nesses locais. Uma das mais notáveis veio da região do Times Square em Nova York. Ali, o Deuce era uma das áreas mais degradadas nos anos 1980, segundo descreve um historiador: 
Vendedores de drogas falsas... traficantes de baixo nível, ladrõezinhos... junkies vivendo sozinhos em seus mundos de cocaína e heroína... "besourões" predatórios espionando e buscando captar negócios com menores... michês de todas as idades... transexuais, prostitutas, e gays enrustidos com coceiras atrás de algum fetiche homo ou heterossexual...era comum ver estrelas pornôs cujos filmes estavam passando nos teatros adultos das redondezas...Você é um freak? Não quando você botava o pé no Deuce. Ser um louco te daria dinheiro, atenção, entretenimento, uma ponta estrelando um filme. Ou talvez um assalto e uma surra. ${ }^{4}$

Posteriormente, a cidade viveu um processo de revitalização e requalificação urbanas emulado justamente nessas regiões, retirando a prostituição e as casas de vídeos pornôs. Parte importante do processo foi o controle da corrupção policial associada à prostituição e ao tráfico de drogas.

Este tipo de estratégia ficará associado posteriormente aos Business Improvement Districts (Bid). De uma forma geral, eles são descritos como "as self-imposed financing mechanisms implemented by business and property owners for local improvements, specifically the enhancement of public services" (Briffault, 1999; Hoyt, 2004; Gross, 2005). Inicialmente desenvolvidos em diversas cidades dos Estados Unidos, e depois utilizados em Nova York, hoje são aplicados em larga escala em diversas cidades norte-americanas. Trata-se de conjugar esforços públicos e privados para o desenvolvimento econômico local, no qual a segurança é um componente preliminar, de forma que um só se faz com a presença do outro. A segurança pública é um serviço público essencial a ser provido e que precede, passando a ser parte integral do progresso econômico da cidade em diversos setores. Para que áreas como Times Square se desenvolvessem, houve um esforço concentrado no serviço público da segurança, com reforço de policiamento e reformas institucionais. $\mathrm{O}$ foco passa a ser no restabelecimento da ordem local em suas mais diversas dimensões urbanística, social e de deterioração do espaço público. Muitas vezes vimos o mesmo tipo de motivação na recuperação de espaços, em diferentes centros urbanos. O hibridismo público e privado na recuperação desses locais é marca crescente dos projetos de intervenção em diversos países e cidades.

\section{Reescrevendo narrativas latino-americanas}

Cada administração municipal mostra uma nova face que termina compondo o mosaico de exemplos emblemáticos em alguns dos grandes centros latino-americanos. São experiências evanescentes com o desejo comum de alterar e fortalecer traços e salvaguardas para a proteção de seus habitantes. Cidades estão em continua mutação e, se necessitam mudar, é porque é sua natureza. Essa é a dinâmica que vemos em Medellin, no bairro da Lagoinha em Belo Horizonte, ou nas cracolândias das grandes centros urbanos latino-americanas. Como mudanças podem se dar de forma virtuosa? Como tornar o ar respirável, especialmente nos bolsões de pobreza? É possível rever paisagens familiares e hostis e transmutá-las em visões virtuosas e rejuvenescidas? 
Vários centros urbanos na América Latina desenvolveram projetos de requalificações urbanas extremamente inovadores, com impactos importantes na segurança. No Chile, "Hermoseando tu Barrio", na Comuna de Puente Alta em Villa El Caleuche, foi um projeto habitacional que inaugurou a política chilena recente de habitação. Tratou-se de um projeto de conjunto habitacional implantado em 36 quarteirões, sob o pretexto do incremento de violência juvenil através de uma pandilla que estava gerando muita insegurança à população de Caleuche. $\mathrm{O}$ primeiro passo foi um diagnóstico junto à comunidade, realizado através de assembleias com os moradores, que terminou colocando o problema das pandillas num feixe de outras questões de natureza urbanística. O primeiro deles era a homogeneidade das habitações, bem como a ausência de espaços públicos de convivência, iluminação e de identidade ambiental através de cores e de espaços diversos.

O passo seguinte foi uma mobilização dos moradores para melhorar o bairro, como a pintura de casas e muros e melhoramentos dos espaços públicos. Nesse momento passam a participar os membros das gangues, cujo ingresso no projeto se dá pela mediação de ex-membros, que passou a envolvê-los através da pintura de grafitti nos muros. Posteriormente, iniciam-se as discussões acerca dos temas de delinquência no bairro. Importante destaque é o processo de articulação dos moradores locais para a solução de problemas, e o processo de empoderamento daí decorrente. A coesão resultante levou a uma transformação física e ambiental, mas que traduziu-se em mais controle e autodeterminação local.

O Rio de Janeiro viu prosperar uma série de inciativas que buscaram lidar com a urbanização de favelas, inserindo-as no grid urbano dos bairros convencionais. Um deles foi o Programa Favela Bairro, construído a várias mão por diferentes secretarias municipais. Idealizado pelo arquiteto e, posteriormente, alcaide da cidade do Rio de Janeiro, terminou tornando-se um modelo de políticas públicas por agências internacionais. Posteriormente, outra administração concebeu uma estratégia de intervenção de atuação em locais de concentração de desordens, buscando reestabelecer as condições de segurança através de um "Choque de Ordem". Segundo Piquet Carneiro (2011), essas ações se deram mediante alguns conceitos orientadores do projeto, que buscou a) atuar nas causas imediatas de desordem, especialmente as relativas aos aspectos físicos do meio ambiente urbano e as posturas e leis municipais que as regulam, estabelecendo padrões claros e possíveis de serem cumpridos pela população; e b) exercício de fiscalização e controle de posturas municipais mais relevantes para o problema. Além disso, trata-se de uma estratégia que busca não concentrar em grupos sociais, mas em comportamentos de desordem.

Tanto no Rio como na inciativa chilena, o desafio era comunicar, integrar e articular os diversos universos urbanos existentes. 


\section{Criando Bases Institucionais para requalificação urbana}

Jane Jacobs (2003, p.138) acreditava que cidades eram diferentes para pessoas diferentes, mas poderiam ser apreendidas numa contemplação mais abrangente: "Para compreender as cidades, precisamos admitir de imediato, como fenômeno fundamental, , as combinações ou as misturas de usos, não os usos separados". Mas a diversidade que Jane Jacobs enxergava como vital para as cidades não anteviu a possibilidade de essas comunidades serem absolutamente incomunicáveis, envoltas em códigos próprios e sem tradução para seus vizinhos. Esse é dos temas centrais da segregação urbana e dos enclaves fortificados criados nos espaços urbanos (Caldeira, 2000). Centro e periferia tornam-se os polos de estruturação narrativa. É possível reinventar o reconhecimento em espaços tão próximos, mas díspares? Não são palavras que irão preencher o vazio da invisibilidade.

Esse mosaico é a essência das imagens de desordem e medo. Nesse jogo, a regra para sua compreensão são os mecanismos de controle que conferem algum grau de organização à desordem inerente desse conjunto de ruas, becos e vielas. Alguns lugares, para seguirmos na metáfora wittgensteiniana, são mais uniformes que outros: o simbolismo químico e a notação infinitesimal são os subúrbios elegantes da cidade; a lógica e a filosofia são partes antigas, e assim por diante. Assim, para andar pelas cidades, necessitamos também de regras. Existem regiões que podem ser visitadas desde que tenhamos uma orientação adequada de como transitarmos ali: um mapa que nos oriente sobre o sentido que devemos tomar, qual a direção, em que momento etc. São instruções conduzindo-nos a trajetos que, ao percorrê-los, percebemos que nos fornecem uma paisagem característica do mundo que nos cerca. Narrativas constituem-se em realidades, versões possíveis de uma reelaboração conceitual.

O bairro da Lagoinha, em Belo Horizonte, foi berço da cidade, e onde viviam os operários que a construíram. Foi também onde os imigrantes italianos foram viver, e criaram uma região efervescente. Em virtude de um processo de reurbanização desordenado, com a construção de viadutos e linhas férreas que terminaram por isolar o bairro do centro da cidade, terminou abrigando uma das maiores "cracolândias", com centenas de usuários ao longo de alguns hotspots. Com a proeminência de gangues de traficantes, rapidamente tornou-se uma das áreas mais deterioradas da cidade. Ao longo de 2018 e 2019, um projeto de requalificação empreendido por diversas secretaria da prefeitura de Belo Horizonte terminou por requalificar urbanística e economicamente um dos eixos mais centrais do bairro, onde um dos elementos centrais foi a arte urbana através dos grafites. Com isso, os homicídios na região começaram a cair de uma média de 30, para 0 em 2019.

Um dos casos mais notáveis de reconstrução narrativa em anos recentes na América Latina foi a empreendida em Medellin. Essa reelaboração inicia-se com Projetos Urbanos Integrais (PUI), uma metodologia de intervenção urbana que 
passou a ser implementado em 2004. Por uma iniciativa de Empresa de Desarrollo Urbano (EDU), atuam em territórios delimitados em diversas comunas da cidade. Trata-se de iniciativa que intervém em diversas dimensões dentro de um dado território. Os PUI se estruturam a partir de três componentes: físico, social e institucional. No primeiro criam-se ambientes seguros a partir de intervenções no meio ambiente e ações de melhorias em espaços públicos. A requalificação empreendida também lida com as estratégias de consolidação e geração de moradias. O componente social, por sua vez, busca induzir a participação comunitária na identificação e busca de soluções para problemas como delinquência, exclusão social e desigualdade. Trata-se de processos de planejamento participativo através da criação de fóruns de discussão envolvendo as $O N G$, juntas de ação comunal e juntas administrativas locais. Do ponto de vista institucional, parte-se do conceito de integralidade implicando intervenções em diversos níveis, até o manejo transparente de recursos públicos. Nessa dimensão, existe uma etapa de planejamento de ações, seguida por diagnósticos, implementação até a entrega desses projetos (Osorio, 2011).

Outro exemplo é a experiência de Bogotá, ilustrativa pelo enfoque sistêmico e interdisciplinar nesse tipo de abordagem. Se no início dos 1990 Bogotá era sinônimo de descontrole, criminalidade e caos urbano, nos anos 2000 passou a tornar-se sinônimo de experiências bem-sucedidas (Llorente; Rivas. 2005) de revitalização urbana. Foram adotadas estratégias envolvendo o controle do consumo de álcool, cultura de convivência cidadã e autorregulação de comportamento dos cidadãos de Bogotá, bem como intervenções urbanas.

Nas gestões dos prefeitos de Anthanas Mockus e Enrique Peñalosa ocorreram várias intervenções urbanas de porte. Enquanto Mockus (1995-1997) focou em políticas voltadas para a cultura cidadã, Peñalosa preocupou-se mais com a recuperação de "espaços de ordem" (Llorente; Rivas, 2005). Para tal, em 1999 foi criado o Departamento Administrativo de Defesa do Espaço Público. Também o Programa Missão Bogotá priorizou a recuperação de espaços críticos de convivência, bem como de reformulação da mobilidade (Acero, 2006). Como resultado dessas intervenções em áreas degradas, o homicídio caiu 60\% de 1995 a 2003. No caso de Cartucho, os resultados em relação ao roubo foram de um decréscimo de 70\% entre 2000 e 2003.

Como lidar com situações dessa natureza, em que se mesclam deterioração urbana, índices socioeconômicos deteriorados, com baixos níveis de controle e eficácia coletiva, bem como instituições de justiça criminal fracas?

\section{Organização em rede com stakeholders}

Uma estratégia adotada, especialmente em áreas comerciais, tem a ver com a mobilização de interessados em solucionar problemas locais de segurança. Essa metodologia foi adotada com sucesso no caso dos BID, que discutimos acima. Isso é particularmente frutífero quando se trata de comerciantes ou empresários em áreas comerciais. O número e o alcance dos stakeholders envolvidos 


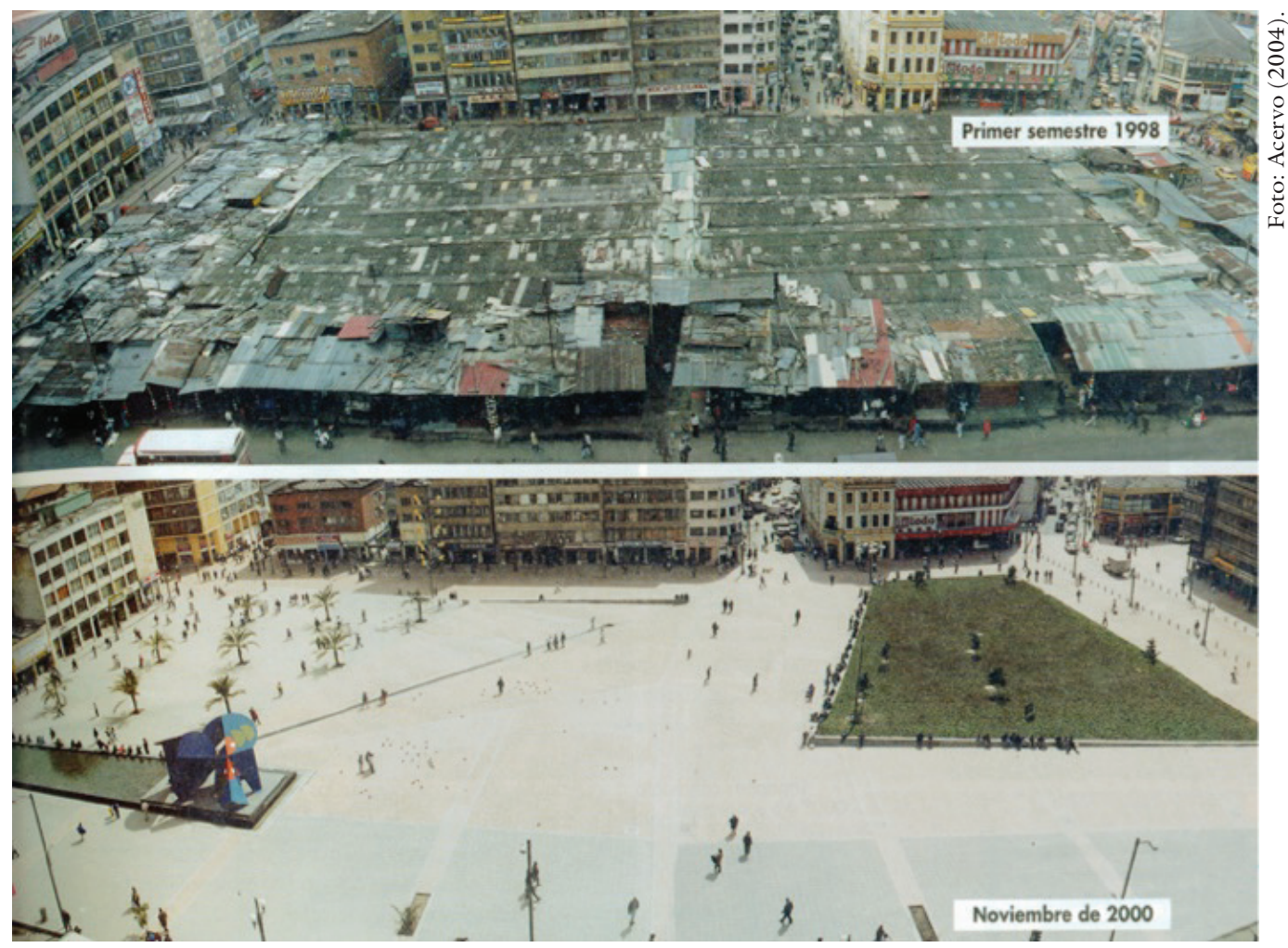

Intervenção urbana em Cartucho, no bairro de Santa Inés em Bogotá, na Colômbia.

irão variar de acordo com a natureza e a complexidade do problema. Podem ser mobilizados desde proprietários de imóveis, inquilinos, associações comunitárias, associações de comerciantes, instituições como escolas clubes, entidades culturais, até instituições oficiais de governo local, polícia etc. (Zahm, 2007).

Assim, projetos comunitários de segurança, especialmente envolvendo a polícia, encontram condições mais favoráveis quando existem interesses locais para essa articulação (Beato, 2004). No caso de Bogotá, foram criadas com o apoio da Câmara de Comércio as "Zonas Seguras", na qual foram definidas algumas quadras em áreas comerciais, onde a polícia com o apoio da comunidade teria uma presença permanente. Esse programa era parte integrante de um eixo mais amplo de fortalecimento da Polícia Metropolitana que incluía melhorias na comunicação e mobilidade, infraestrutura, capacitação, polícia de proximidade, gestão para o trânsito e modificações gerenciais (Acero, 2006).

\section{A construção de cavalos de Troia}

Uma das consequências que têm a ver com a insegurança e o medo é que essas condições minam a qualidade de vida. Contudo, nem sempre essas condições podem ser satisfeitas. A precariedade de capital social nas áreas extremamente empobrecidas que a migração de grandes contingentes populacionais terminou criando em muitas dos hotspots de violência também é outro componente a ser tomado em consideração nas dificuldades que enfrentam os projetos. Daí a 
necessidade de termos estratégias a serem exploradas na exploração de redes de relações entre moradores, lideranças, servidores públicos que se veem às voltas com as atividades de gangues em seus territórios.

De certa maneira, são as intervenções indiretas de controle social, que consistem em atuar na infraestrutura urbana e melhoramentos nos bairros, mas que, sob determinadas condições, parecem ter efeitos sobre a insegurança e a violência. Em condições de extrema vulnerabilidade e pobreza, intervenções de natureza urbanística e provisão de infraestrutura podem se constituir numa boa forma para catalisar processos de empoderamento e consequente controle social, mediante a participação de atores e lideranças locais em parceria com autoridades. Isso ocorrerá se dadas condições adequadas para que as ações de engenharia e urbanismo possam prosperar, bem como das emergência de novas redes de relações locais que terminem melhorando as condições de segurança.

Esse último aspecto é de particular interesse, porque ele parte justamente de intervenções físicas genéricas, mas que terminam constituindo-se numa espécie de "Cavalo de Troia" para que condições locais de segurança prosperem pela forma como o processo é conduzido. Muitas intervenções de caráter integral e participativo podem ser classificadas nesse tipo.

Uma atenção especial deve ser conferida às redes locais que tornam possível ou inviabilizam o exercício de controle social por parte dos moradores, bem como sua relação com as instituições públicas. Os tipos de articulação existentes entre grupos e organizações locais são cruciais para compreendermos como se exerce a capacidade local de controle de comportamento sobre jovens e grupos que estejam comprometendo as condições de segurança.

\section{À guisa de conclusão}

Ao fim e ao cabo, talvez devêssemos aprender com o personagem a refletir sobre Alexandria, em Justine, de Lawrence Durrel, para quem "nenhum de nós é responsável pelo que se passou. É a cidade que deve ser julgada, embora seja sobre nós, os seus filhos, que recaia a punição". Nossas cidades possuem dinâmica e vida próprias, que devemos aprender a conhecer, respeitar e conviver. Elas guardarão suas marcas indeléveis em nós, e quaisquer coisas que desejamos alterar deverão respeitá-las.

Não existe outra terra, meu amigo, nem outro mar,

Porque a cidade irá atrás de ti; as mesmas ruas

Cruzam sem fim as mesmas ruas; os mesmos

Subúrbios do espírito passam da juventude à velhice,

E tu perderás os teus dentes e os teus cabelos

Dentro da mesma casa. A cidade é uma armadilha.

Só este porto te espera,

E nenhum navio te levará onde não podes.

Ah! então não vês que te desgraçaste neste lugar miserável 
E que a tua vida já não vale nada,

Nem que vás procurá-la nos confins da terra?

Konstantinos Kavafis

Justine, Lawrence Durrell, 1986

tradução de Daniel Gonçalves

Notas

1 Disponível em: <https://homicide.igarape.org.br; https://knoema.com/UNOD CHIS2015/unodc-international-homicide-statistics-2014>; <http:/www.vanderbilt. edu/lapop/ab2014/AB2014_Comparative_Report_English_V3_revised_011315_W. pdf>.

2 Disponível em: <https://www.economist.com/graphic-detail/2017/03/31/the-worlds-most-dangerous-cities $>$.

3 Disponível em: <http://www.vanderbilt.edu/lapop/ab2014/AB2014_Comparative_Report_English_V3_revised_011315_W.pdf>.

4 "phony drug salesman ... low-level drug dealers, chain snatchers ... [j] unkies alone in their heroin/cocaine dreamworld ... predatory chickenhawks spying on underage trade looking for pickups... male prostitutes of all ages... [t] ranssexuals, hustlers, and closety gays with a fetishistic homo- or heterosexual itch to scratch ... It was common to see porn stars whose films were playing at the adult houses promenade down the block. ... Were you a freak? Not when you stepped onto the Deuce. Being a freak there would get you money, attention, entertainment, a starring part in a movie. Or maybe a robbery and a beating."

Referências

ACERO, V. H. Os governos locais e a segurança cidadã. World Bank, 2006.

BEATO, C. Reinventar la policía: la experiencia de Belo Horizonte. In: Calles más seguras. Washington: Inter American Development Bank, 2004. v.1, p.100-34. . Crime e cidades. Belo Horizonte: Editora UFMG, 2012.

BRATTON, W. Turnaround. How America's Top Cop Reversed the Crime Epidemic. New York: Random House, 1998.

BRIFFAULT, R. A Government for our Time? Business Improvement Districts and Urban Governance. Columbia Law Review, v.99, n.365, 1999.

CALDEIRA, T. P. R. Cidade de muros. Crime, segregação e cidadania em São Paulo. São Paulo: Editora 34; Edusp, 2000.

CALVINO, I. As cidades invisípeis. São Paulo: Cia. das Letras, 1990.

CRISP, 2012. Relatório I Pesquisa Nacional de Vitimização. www.crisp.ufmg.br

DURREL, L. Justine. Lisboa: Ulisseia, 1986.

GROSS, J. S. Business Improvement Districts in New York City's Low-Income and High-Income Neighborhoods. Economic Development Quarterly, v.19, n.2, p.174-89, May 2005. 
HOBBES, T. Leviatã. In: Os pensadores. São Paulo: Abril, 1979.

HOYT, L. Collecting private funds for safer public spaces: an empirical examination of the business improvement district concept. Environment and Planning B: Planning and Design, v.31, p.367-80, 2004.

JACOBS, J. Morte e vida das grandes cidades. São Paulo: Martins Fontes, 2003.

LEVI-STRAUSS, C. Tristes trópicos. In: Os pensadores. São Paulo: Abril, 1980.

LISPECTOR, C. Mineirinho. In: Para não esquecer. São Paulo: Ática, 1979.

LLORENTE, M. V.; RIVAS, A. Estudio de caso: la caída del crimen en Bogotá: una decada de políticas de seguridad ciudadana. Word Bank. Departamento de Finanza, Sector Privado e Inraestructura. Washington DC.: PAMUK, Ohran, 2005. [Istambul. Companhia das Letras]

MAPLE, J. The crime fighter. New York: Broadway Books, 1999.

OSORIO, D. P. Proyectos Urbanos Integrales - PUI. In Laboratório Medellín. Catalogo de Diez Práctivas Activas. Alcaldía de Medellín, 2011.

PIQUET CARNEIRO, L. Segurança. Qual o papel dos municípios? Seminário na Fundação João Pinheiro, Belo Horizonte. Minas Gerais. 2011. Disponível em: <http:// www.youtube.com/watch?v=ilfixwMYxZs $>$.

SENNET, R. The Uses of Disorder: Personal Identity and City Life. New York. W.W. Norton, 1970.

WIESBURD, D.; GROFF, E.; YANG, S.-M. The Criminology of Place. Street Segments and our Understanding of the Crime Problem. Oxford University Press, 2012.

WITTGENSTEIN, L. Investigações filosóficas. In: . Os pensadores. São Paulo: Abril, 1980.

ZAHM, D. Using Crime Prevention trough Envirnmental Design and Problem Solving. COPS/US Department of Justice. Problem-Oriented Guides for Police Problem-Solving Tools Series, n.8, 2007.

RESUMO - Este ensaio irá discutir como ambientes urbanos afetam a sensação de medo, e a qualidade de vida das pessoas. Estes sentimentos tem sido um importante componente da vida urbana nos grandes centros brasileiros e latino-americanos. Esta será uma reflexão sobre algumas possibilidades de lidar com este problema. Especificamente, trataremos das intervenções de requalificação e revitalização urbanas.

PALAVRAS-CHAVES: Cidades e crime, Medo, Revitalização urbana.

ABSTRACT - This essay will discuss how urban environments affect the feeling of fear and people's quality of life. This feeling has been an important component of urban life in large Brazilian and Latin American urban centers. This will be a reflection on some 
possibilities of dealing with this problem. Specifically, we will deal with urban redevelopment and revitalization interventions.

KETWORDS: Cities and crime, Fear, Urban revitalization.

Claudio Beato é coordenador Centro de Estudos em Criminalidade e Violência (Crisp), da Universidade Federal de Minas Gerais. @ - claudiobeato@crisp.ufmg.br https://orcid.org/0000-0002-0145-7454

I Universidade Federal de Minas Gerais, Belo Horizonte, Minas Gerais, Brasil.

Recebido em 30.5.2019 e aceito em 18.6.2019. 